\title{
PERSPECTIVE TDP1 INHIBITORS BASED ON ADAMANTANE, MONOTERPENE AND HETEROCYCLIC MOIETIES
}

\section{A. Munkuev', A. Zakharenko², E. Suslov' ${ }^{1}$ A. Chepanova², K. Volcho', N. Salakhutdinov ${ }^{1}$ and O. Lavrik ${ }^{2}$}

${ }^{1}$ N.N. Vorozhtsov Novosibirsk Institute of Organic Chemistry, Siberian Branch of Russian Academy of Sciences, 630090, Russia, Novosibirsk, Lavrentiev Avenue, 9.

${ }^{2}$ Institute of Chemical Biology and Fundamental Medicine, Siberian Branch of Russian Academy of Sciences, 630090, Russia, Novosibirsk, Lavrentiev Avenue, 9.

DOI: 10.19163/MedChemRussia2021-2021-367

E-mail:amunkuev@nioch.nsc.ru

Tyrosyl-DNA phosphodiesterase 1 (Tdp1) is a DNA repair enzyme that is responsible for drug resistance of at least some cancer types. It is believed that inhibition of this enzyme could increase efficacy of frontline antitumor drugs topotecan and irinotecan [1]. Therefore, developing effective Tdp1 inhibitors is of great interest in modern medicinal chemistry.

We synthesized compound I that has been transformed into the corresponding 1,2,4-triazole and 1,3,4-thiadiazole derivatives under alkaline and acidic conditions respectively, followed by the modification of heterocyclic compounds with monoterpenoid residues having acyclic, monocyclic or bicyclic structures [2].
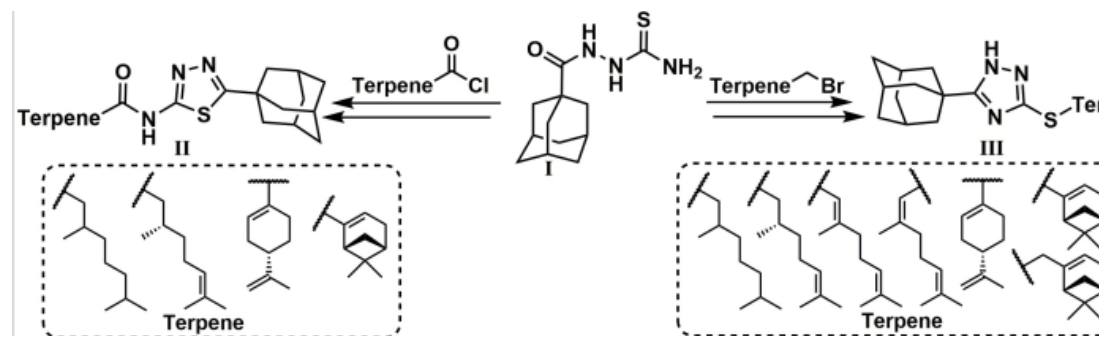

The compounds were tested for their Tdp1 inhibitory properties. It was shown that all the compounds exhibited inhibitory activity at submicromolar and micromolar concentrations. Furthermore, 1,3,4-thiadiazoles II and 1,2,4-triazoles III, containing acyclic unsaturated chain or $\alpha$-pinene fragments were found to have a sensitizing effect in conjunction with topotecan in the HeLa cervical cancer and colon adenocarcinoma HCT-116 cell lines.

This work is supported by the Russian Science Foundation under grant 19-13-00040.

\section{References}

[1] M. Kciuk et al., Int. J. Mol. Sci.. 2020, 14, 1-21.

[1] A. Munkuev et al., Molecules. 2021, 14, 3128. 